\title{
EFFICACY OF ORAL ZINC SULPHATE VERSUS TOPICAL APPLICATION OF SALICYLIC ACID (16.7\%) \& LACTIC ACID (16.7\%) COMBINATION IN THE TREATMENT OF PLANTAR WARTS
}

\author{
DR. AZKA IQBAL, MBBS \\ Nishtar Hospital, Multan, Pakistan. \\ DR. NOOR-UL-AIN, MBBS \\ Nishtar Hospital, Multan, Pakistan. \\ DR. YASIR IQBAL, MBBS \\ District Headquarters teaching Hospital, Sahiwal, Pakistan.
}

\begin{abstract}
Background; Warts are common epidermal growths caused by human papillomavirus that often cause significant discomfort and embarrassment. Current treatment options include topical therapies, cryotherapy, laser vaporization, and surgical excision. Objective: To compare the efficacy of oral zinc sulphate versus topical application of salicylic acid (16.7\%) \& lactic acid (16.7\%) combination in the treatment of plantar warts. Material and Methods; One hundred and fifty six patients with warts fulfilling the inclusion and exclusion criteria coming in Medicine outpatient department were included in the study. Group A, having 78 patients, was given oral zinc sulphate $(10 \mathrm{mg} / \mathrm{kg} /$ day $)$ in two or three divided doses. In group B, 78 patients were advised to apply a combination of salicylic (16.7\%) \& lactic acid (16.7\%) once at night daily. Results; Of these 156 study cases, $94(60.3 \%)$ were male patients while $62(39.7 \%)$ were female patients. Mean age of our study cases was $34.42 \pm 9.87$ years. Monthly family income up to Rs. 30000 was noted in 68 (43.6\%) while $88(56.4 \%)$ had monthly family income more than Rs. 30000. Mean weight of our study cases was $61.96 \pm 10.29$ kilograms. Mean height of our study cases 161.24 \pm 12.23 centimeters. Mean BMI of our study cases was $26.52 \pm 1.87 \mathrm{~kg} / \mathrm{m}^{2}$ and obesity was present in $31(19.9 \%)$ of our study cases. Mean no. of lesions was noted to be $5.30 \pm 2.45$ lesions (with minimum no. of lesions was 4 and maximum no. of lesions was 10) and 131 (84\%) had up to 5 lesions. Mean duration of disease was $4.69 \pm 1.61$ months and $112(71.8 \%)$ had disease duration up to 6 months. Efficacy was noted in $110(70.5 \%)$. Efficacy in group A was noted to be $83.3 \%$ and in group B was $57.7 \%(\mathrm{p}=0.001)$.

Conclusion; Our study results support the use of oral Zinc Sulphate in the treatment of plantar warts as compared to the salicylic acid (16.7\%) and lactic acid (16.7\%) combination. Efficacy of Zinc Sulphate was significantly higher when compared with combination therapy and it was found to be safe and reliable mode of treatment having no side effects were observed in our study. Use of Zinc Sulphate can help to reduce chance of recurrence and disease morbidity. Being cost effective, it provides cheaper mode of treatment as compared with cryotherapy which is quite expensive which will provide economic relief to our large poor population. Early treatment can help patients to maintain routine daily lives and physical activities such as sports without any pain and side effects.

Keywords; Plantar warts, Zinc Sulphate, Salicylic acid, lactic acid.
\end{abstract}

DOI: $10.7176 / \mathrm{JMPB} / 52-09$

\section{INTRODUCTION}

Wart is a mucocutaneous disease that develops as a result of proliferation of infected skin or mucosal cells with human papilloma virus (HPV). ${ }^{1}$ They range in size from less than $1 \mathrm{~mm}$ to over $1 \mathrm{~cm}$ and can form large masses when confluent. ${ }^{2}$. Different clinical forms of warts include common warts, palmoplantar warts, flat warts, filiform warts and anogenital warts. ${ }^{3}$ Human papillomaviruses (HPVs) are a group of more than 100 DNA viruses that infect human epithelial cells. ${ }^{4}$ The majority of common warts are caused by HPV types 1,2,4,27,57 and plane warts by 3 and $10^{5}$.

A plantar wart (also called verruca plantaris) is a lesion that appears on the plantar surface of foot as a small, shining, sago-grain papule which soon assumes the typical appearance of a sharply-defined rounded lesion with a rough keratotic surface surrounded by a smooth collar of thickened horn. Warts occur at any age, but are common among children. It is estimated that $7-10 \%$ of the United States (US) population have plantar warts. The virus can survive many months without a host, making it highly contagious. Plantar warts are caused by infection with human papilloma virus types 1,2,4 and 63. The virus attacks the skin through direct contact, entering via tiny cuts and abrasions in the stratum corneum. The common sites of plantar warts are beneath pressure points (the heel or the metatarsal heads). The duration of plantar warts is very variable. Spontaneous regression occurs sooner in children. In adults, warts may persist for years ${ }^{6}$. Plantar warts (PW) may sometimes resolve spontaneously, with 
their natural course usually being shorter in children than adults, although resolution may take several years. The treatment of PW has involved several different modes, including ablative therapy and other options that modify the immune response ${ }^{7,8}$.

The topical application of salicylic and lactic acid combination in a collodion is a common form of treatment with once daily application. It is an effective treatment option with few side effects. It is used as an initial therapy for treatment of plantar warts with minimum cost and minimal pain. Salicylic acid causes keratolysis thus helps in removing the thickened epidermis. Oral zinc sulphate is also an effective therapy in the treatment of warts. Zinc has an important effect on the immune system and it has been used as an immunomodulator to treat a variety of skin disorders ${ }^{9-12}$. Efficacy with oral Zinc sulphate is reported to be $82 \%$ while $62 \%$ topical application of salicylic acid $(16.7 \%) \&$ lactic acid (16.7\%) combination ${ }^{6}$.

\section{MATERIAL AND METHODS:}

Patients of both genders having plantar warts (hyperkeratotic firm papules with a rough surface. Plantar warts were diagnosed clinical judgment of rough surface, well defined border and pain on pressure) aged $20-60$ years having disease duration more than 3 months were taken. Pregnant and lactating women, those who are already taking treatment and known cases with previous history of drug allergy were excluded from our study. One hundred and fifty six patients with warts fulfilling the inclusion and exclusion criteria coming in Medicine outpatient department were included in the study. Group A, having 78 patients, was given oral zinc sulphate $(10 \mathrm{mg} / \mathrm{kg} / \mathrm{day})$ in two or three divided doses. In group B, 78 patients were advised to apply a combination of salicylic $(16.7 \%) \&$ lactic acid $(16.7 \%)$ once at night daily. In group A, using oral zinc sulphate, the treatment was given for two months and follow up continued for next 1 month. In group B, the topical preparation was also continued for 2 months or till the complete removal of wart (if before two months) and follow up was extended up to 1 month after treatment. All data was entered using software SPSS version 22. Mean and standard deviation was calculated for age, height, weight, BMI, number of lesions and duration of disease of patients. Frequencies and percentages were calculated for gender, obesity, family income, residential status and efficacy of drugs in both groups. Chisquare test was applied to compare the efficacy in both groups and $p$ value was considered significant if $\leq 0.05$.

\section{RESULTS}

Our study registered a total of 156 study cases meeting inclusion criteria of our study from OPD of department of Medicine, Nishtar Hospital, Multan. Of these 156 study cases, 94 (60.3\%) were male patients while 62 (39.7\%) were female patients. Mean age of our study cases was $34.42 \pm 9.87$ years (with minimum age was 21 years while maximum age was 54 years). Mean age of our study cases in group A was $34.62 \pm 9.95$ years while in group B was $34.23 \pm 9.85$ years $(\mathrm{p}=0.809)$. Our study results have reported that majority of our study cases i.e. 103 $(66 \% \%)$ belonged to age group of $20-40$ years of age. Of these 156 study cases, $55(35.3 \%)$ were from rural areas while 101 (64.7\%) were from urban areas. Monthly family income up to Rs. 30000 was noted in $68(43.6 \%)$ while $88(56.4 \%)$ had monthly family income more than Rs. 30000. Mean weight of our study cases was $61.96 \pm 10.29$ kilograms (with minimum weight was 54 kilograms and maximum was 94 Kilograms). Mean height of our study cases $161.24 \pm 12.23$ centimeters. Mean BMI of our study cases was $26.52 \pm 1.87 \mathrm{~kg} / \mathrm{m}^{2}$ and obesity was present in $31(19.9 \%)$ of our study cases. Mean no. of lesions was noted to be $5.30 \pm 2.45$ lesions (with minimum no. of lesions was 4 and maximum no. of lesions was 10) and 131 (84\%) had up to 5 lesions. Mean duration of disease was $4.69 \pm 1.61$ months and $112(71.8 \%)$ had disease duration up to 6 months. Efficacy was noted in $110(70.5$ $\%)$. Efficacy in group A was noted to be $83.3 \%$ and in group B was $57.7 \%(p=0.001)$.

\section{DISCUSSION}

Cutaneous warts are benign epidermal proliferations caused by Human Papilloma viruses (HPV) ${ }^{13-15}$. Viral warts are common afflictions, affecting mostly children and young adults. Humoral immunity provides sufficient protection against HPV infection. If the infection does develop, innate and adaptive cell mediated immunity is important for the eventual elimination of the infection. However, the reasons for apparent failure of the immune system in otherwise healthy individuals to clear warts for months or years remains incompletely understood. Viral warts among these individuals do not respond to conventional therapies or soon recur after destructive procedures and persist for months and years altogether till the time, the balance turns in favour of the immune system and the warts cease to exist ${ }^{16}$.

Our study registered a total of 156 study cases meeting inclusion criteria of our study from OPD of department of Medicine, Nishtar Hospital, Multan. Of these 156 study cases, 94 (60.3\%) were male patients while 62 (39.7\%) were female patients. Such male gender preponderance has also been reported by Raza et al ${ }^{16}$ who reported $69 \%$ male gender predominance which is similar to our study results. While a study conducted Bruggink et al ${ }^{17}$ reported $56 \%$ female gender preponderance which is different from our study results. 
Mean age of our study cases was $34.42 \pm 9.87$ years (with minimum age was 21 years while maximum age was 54 years). Mean age of our study cases in group A was $34.62 \pm 9.95$ years while in group B was $34.23 \pm 9.85$ years $(\mathrm{p}=0.809)$. Our study results have reported that majority of our study cases i.e. $103(66 \% \%)$ belonged to age group of $20-40$ years of age. Raza et al ${ }^{16}$ also reported viral warts being predominating 20 - 30 years age group which is similar to our study results. A study conducted by Cockayne et al ${ }^{13}$ reported 24.3 years mean age of the patients with warts which is similar to our study results.

Of these 156 study cases, 55 (35.3\%) were from rural areas while 101 (64.7\%) were from urban areas. Monthly family income up to Rs. 30000 was noted in 68 (43.6\%) while 88 (56.4\%) had monthly family income more than Rs. 30000. Mean weight of our study cases was $61.96 \pm 10.29$ kilograms (with minimum weight was 42 kilograms and maximum was 85 grams). Mean height of our study cases $161.24 \pm 12.23$ centimeters. Mean BMI of our study cases was $26.52 \pm 1.87 \mathrm{~kg} / \mathrm{m}^{2}$ and obesity was present in $31(19.9 \%)$ of our study cases.

Mean no. of lesions was noted to be $5.30 \pm 2.45$ lesions (with minimum no. of lesions was 4 and maximum no. of lesions was 10) and 131 (84\%) had up to 5 lesions. A study conducted by Cockayne et al ${ }^{13}$ documented mean no. of lesions were $4.0 \pm 6.6$ which is in compliance with that of our study results.

Mean duration of disease was $4.69 \pm 1.61$ months and $112(71.8 \%)$ had disease duration up to 6 months. Raza et al ${ }^{16}$ and Cockayne et al ${ }^{13}$ reported similar results.

Efficacy was noted in 110 (70.5\%). Efficacy in group A was noted to be $83.3 \%$ and in group B was $57.7 \%$ ( $\mathrm{p}=$ 0.001 ). A study conducted by Salman et al ${ }^{6}$ reported efficacy with oral Zinc sulphate to be $82 \%$ while $62 \%$ topical application of salicylic acid (16.7\%) \& lactic acid (16.7\%) combination. These findings are close to our study results.

\section{CONCLUSION;}

Our study results support the use of oral Zinc Sulphate in the treatment of plantar warts as compared to the salicylic acid $(16.7 \%)$ and lactic acid (16.7\%) combination. Efficacy of Zinc Sulphate was significantly higher when compared with combination therapy and it was found to be safe and reliable mode of treatment having no side effects were observed in our study. Use of Zinc Sulphate can help to reduce chance of recurrence and disease morbidity. Being cost effective, it provides cheaper mode of treatment as compared with cryotherapy which is quite expensive which will provide economic relief to our large poor population. Early treatment can help patients to maintain routine daily lives and physical activities such as sports without any pain and side effects.

\section{REFERENCES;}

1. Zamanian A, Mobasher P, Jazi GA. Efficacy of intralesional injection of mumps-measles-rubella vaccine in patients with warts. Adv Biomed Res. 2014;3:107.

2. España LP, Boz JD, Morano TF, Villafranca JA, Martín MT. Topical cidofovir for plantar warts. Dermatol Ther. 2014 Mar-Apr;27(2):89-93.

3. Moore $\mathrm{E}^{1}$, Kovarik $\mathrm{C}^{2}$. Intralesional cidofovir for the treatment of a plantar wart. J Am Acad Dermatol. 2015 Jul;73(1):e23-4. doi: 10.1016/j.jaad.2015.02.1143.

4. Juckett G, Hartman-Adams H. Human papillomavirus: clinical manifestations and preventation. Am Fam Physician. 2010;82(10):1209-13.

5. Sterling JC, Gibbs S, Hussain HS, Mustapa MF, Jones HE. British Association of Dermatologists' guidelines for the management of cutaneous warts 2014. Br J Dermatol. 2014;171(4):696-712.

6. Salman S, Aman S, Nadeem M, Kazmi AH. Oral zinc sulphate versus topical application of salicylic acid and lactic acid combination in the treatment of plantar warts. Ann King Edward Med Uni. 2014;20(1):49-54.

7. Stamuli $E^{1}$, Cockayne S, Hewitt C, Hicks K, Jayakody S, Kang'ombe AR, et al. Cost-effectiveness of cryotherapy versus salicylic acid for the treatment of plantar warts: economic evaluation alongside a randomised controlled trial (EVerT trial). J Foot Ankle Res. 2012 Feb 27;5:4. doi: 10.1186/1757-1146-5-4.

8. Gupta $\mathrm{R}^{1}$, Gupta $\mathrm{S}^{2}$. Topical adapalene in the treatment of plantar warts; randomized comparative open trial in comparison with cryo-therapy. Indian J Dermatol. 2015 Jan-Feb;60(1):102. doi: 10.4103/00195154.147835.

9. Bruqqink SC, Gussekloo J, Berger MY, Zaaijer K, Assendelft WI, de Waal MW, et al. Cryotherapy with liquid nitrogen versus topical salicylic acid application for cutaneous warts in primary care. randomised controlled trial. J Can Med Assoc. 2010;182(15):1624-30.

10. Focht DR, Spicer C, Fairchok MP. Efficacy of duct tape versus cryotherapy in the treatment of verruca vulgaris. Arch Pediatr Adolesc Med. 2002;156(10):971-4.

11. Shaheen MA, Salem SA, Fouad DA, Abd El-Fatah AA. Intralesional tuberculin (PPD) versus measles, mumps, rubella (MMR) vaccine in treatment of multiple warts: a comparative clinical and immunological study. Dermatol Ther. 2015 Apr 6. doi:10.1111dth. 12230. 
12. Anwer MS, Waqas MA, Ali M, Safdar S. Thoracolumber vertebral fractures; outcome of short segment transpedicular fixation. Professional Med J. 2015;22(10):1250-55.

13. Cockayne S, Hewitt C, Hicks K, Jayakody S, Kang'ombe AR, Stamuli E, et al. Cryotherapy versus salicylic acid for the treatment of plantar warts (verrucae): a randomised controlled trial. BMJ 2011;342:d3271.

14. Thappa $\mathrm{DM}^{1}$, Chiramel $\mathrm{MJ}^{1}$. Evolving role of immunotherapy in the treatment of refractory warts. Indian Dermatol Online J. 2016 Sep-Oct;7(5):364-370.

15. Santos-López G, Márquez-Domínguez L, Reyes-Leyva J, Vallejo-Ruiz V. General aspects of structure, classification and replication of human papillomavirus. Rev Médica Inst Mex Seguro Soc. 2015;53(Suppl 2):S166-71.

16. Raza $\mathrm{N}^{1}$, Khan DA. Zinc deficiency in patients with persistent viral warts. J Coll Physicians Surg Pak. 2010 Feb;20(2):83-6.

17. Bruqqink SC, Gussekloo J, Berger MY, Zaaijer K, Assendelft WJ, de Waal MW et al. Cryotherapy with liquid nitrogen versus topical salicylic acid application for cutaneous warts in primary care: randomized controlled trial. J Can Med Assoc. 2010;182(15):1624-30. 